\title{
UNA AGENDA CENTRADA EN LAS PERSONAS:
}

\section{LA AGENDA DE LA OIT TRAS SU CENTENARIO}

\author{
María Luz Vega Ruiz \\ OIT
}

Como bien señala la recientemente aprobada, Declaración del Centenario de las OIT para el Futuro del trabajo ${ }^{1}$ el trabajo de la Organización en pos de la justicia social ha permitido ver logros, y confirmado que sólo el empeño tripartito que siempre estuvo en su origen, puede garantizar la estabilidad del mundo social.

En su segundo siglo de existencia, buscar garantizar que esa tan, aún necesaria, justicia social sea capaz de afrontar los retos de un futuro del trabajo a veces incierto, centrándose en el ser humano, implica que las políticas económicas, sociales y ambientales deben tener en cuenta la protección de los derechos de los trabajadores y las aspiraciones, necesidades y derechos de todas las personas en general.

Una importante lista de mandatos y una agenda detallada de exhortos y declaraciones, estructura, en esta corta Declaración, las discusiones y los acuerdos de una Conferencia relevante tanto por su carácter simbólico (no siempre uno cumple cien años), como por su propuesta para abordar las políticas nacionales en torno a los valores de la OIT y en le marco de los ODS 2030.

Como ya lo hizo el informe de la Comisión Global para el futuro del trabajo (ver número 1/2019 de IUSLabor), la Conferencia insiste en la necesidad de invertir en el fortalecimiento de las capacidades de las personas para que puedan beneficiarse de las ventajas de un mundo en transición, en el fortalecimiento de las instituciones de trabajo para proteger a todos los trabajares, y en el crecimiento económico sostenido, inclusivo y sostenible, el empleo productivo y pleno y el trabajo decente para todos.

Esta Declaración reafirma el valor de las normas intencionales en su doble vertiente de nuevos textos a ser adoptados y en el del cumplimiento de los ya ratificados, así como en la necesidad de consolidar y reforzar a los mandantes tripartitos, abordar los derechos fundamentales a través del dialogo social y participar en todos los procesos pertinentes.

La Declaración del Centenario no inventa la rueda, ni propone modificar el modus operandi de la OIT (que, por otro lado, tan bien ha funcionado, incluso en las épocas de

\footnotetext{
${ }^{1}$ https://www.ilo.org/wcmsp5/groups/public/---ed_norm/--relconf/documents/meetingdocument/wcms_711699.pdf
} 
más arduo conflicto). Es un texto de afirmación de los valores que introduce las nuevas perspectivas y los nuevos cambios.

Desde la visión tradicional de contar con un mundo con justicia social y con el dialogo social como instrumento de cohesión y progreso, reconoce la importancia de empresas sostenibles y generadoras de empleo y la necesidad de condiciones de trabajo sanas y saludables

Apoyándose en la necesidad de un mundo sin acoso y violencia en su preámbulo, la Declaración significa, así, la adopción en el mismo año de su centenario de un nuevo Convenio $^{2}$ para su eliminación, completado por un recomendación ${ }^{3}$, aprobación paralela que cementa la idea de que la dignidad de la persona es el centro del desarrollo de la justicia social.

No cabe duda que la OIT está celebrando su centenario en una coyuntura de profundas transformaciones del mundo del trabajo, como consecuencia de las innovaciones tecnológicas, la evolución demográfica y la mundialización, que determinan en gran medida la forma y el futuro del trabajo, así como la situación y la dignidad de las personas con respecto al mismo. La estrategia formulada en la Declaración marcará los pasos para la acción futura de la OIT.

El fin de las propuestas que el texto contiene no es otro que el de aprovechar las oportunidades y hacer frente a los retos con objeto de forjar un futuro del trabajo justo, inclusivo y seguro, con empleo pleno, productivo y libremente elegido, y trabajo decente para todos, tarea que, sin más tardar, la OIT pretende liderar dentro del sistema de naciones Unidas en los próximos años.

Es mucho el trabajo, pero no es la primera ni la última vez que la OIT enfrenta tales retos, pero el mandato firme de esta Declaración y el compromiso de los que han sido sus actores en los últimos cien años, estamos seguros que la Organización conseguirá el progreso de la mujer y el hombre en un mundo más digno, más igual y más justo

IUSLabor 2/2019, ISSN 1699-2938, p. 153-154

DOI. 10.31009/IUSLabor.2019.i02.12

\footnotetext{
${ }^{2}$ https://www.ilo.org/wcmsp5/groups/public/---ed_norm/--relconf/documents/meetingdocument/wcms_711719.pdf)

${ }^{3} \mathrm{https}$ //www.ilo.org/wcmsp5/groups/public/---ed_norm/--relconf/documents/meetingdocument/wcms_711721.pdf
} 